\title{
AC ELECTRICAL BEHAVIOUR OF MERCURIC IODIDE UNDER DIFFERENT LIGHT INTENSITIES
}

\author{
Mousa M. Abdul-Gader, Khalil $\Lambda$. Wishah, Yusuf M. Mahmud, \\ Marouf Al-Haj Abdallah, Mahrnud A. Hassan, \\ and Riyad N. Ahmad-ritar \\ Department of Physics, University of Jordan, \\ Amman, Jordan
}

\begin{abstract}
The impedance, $\mathrm{Z}$, and phase angle, $\Phi$, of $\mathrm{Hgl}_{2}$ crystal were measured at room temperature as a function of frequency, $f$, in the range $1 \mathrm{~Hz}-20 \mathrm{KHz}$ under different intensities of green light. No appreciable change in $Z$ and $\Phi$ light intensity, $I$, is observed at frequencies higher than $3 \mathrm{KHz}$ suggesting that the effect of light is masked by the frequency-dependent conduction through the capacitance of the crystal bulk. In the low frequency region, however, the effect of light intensity on $Z$ and $\Phi$ is relatively large. For $f<100 \mathrm{~Hz}$, the real part, $Z_{R}$, and imaginary part, $Z_{l}$, of the impedance almost follow a power-law dependance on $l$ of the form $Z_{R}$ or $Z_{I} \propto I^{-m}$ with $m$ is slightly dependent on frequency and ranging from 0.4-0.6 for $Z_{R}$ and $0.7-0.9$ for $Z_{I}$. This variation of $Z_{R}$ and/or $Z_{I}$ is understood in the light of the network proposed by others.
\end{abstract}

\section{nutroduction}

Considefable intetest has been afose up during recent years in the wa of mercuric iodide $\left(\mathrm{H}_{0} \mathrm{~L}_{2}\right)$ as a bw-energy gamma and/or $x=r 8 y$ dctector material at coom temperature $(1-10)$. The actual physical properties of this material are yet not fully undetstood due to several undesinble processes occuring in the crystal that deteriotate the performance of the materia) as a radiation detector (9-17). Several methods hove been used to study a variety of physical properties of $\mathrm{Hgl} / 2$ crystak under the effect of different expetimental parameters in attempt to accompEsh a better understanding of the ekcteical behavious of radiatian detectors made of this material $(9,10,14,15,17-23)$. One of these methoch is the AC impedance technique $(15,16)$ used by Bitat and co-workers to meaure ditectly the complex impedince, 2 . Bnd the phase angle, $\Phi$, of the $\mathrm{Hgl}_{2}$ cell being investigated.

The aim of this poper is to destribe measutements of $Z$ and $\boldsymbol{d}$. using our previous imperance techrique $(15,76)$, of $\mathrm{Hgl}_{2}$ crystals ot room temperature under 


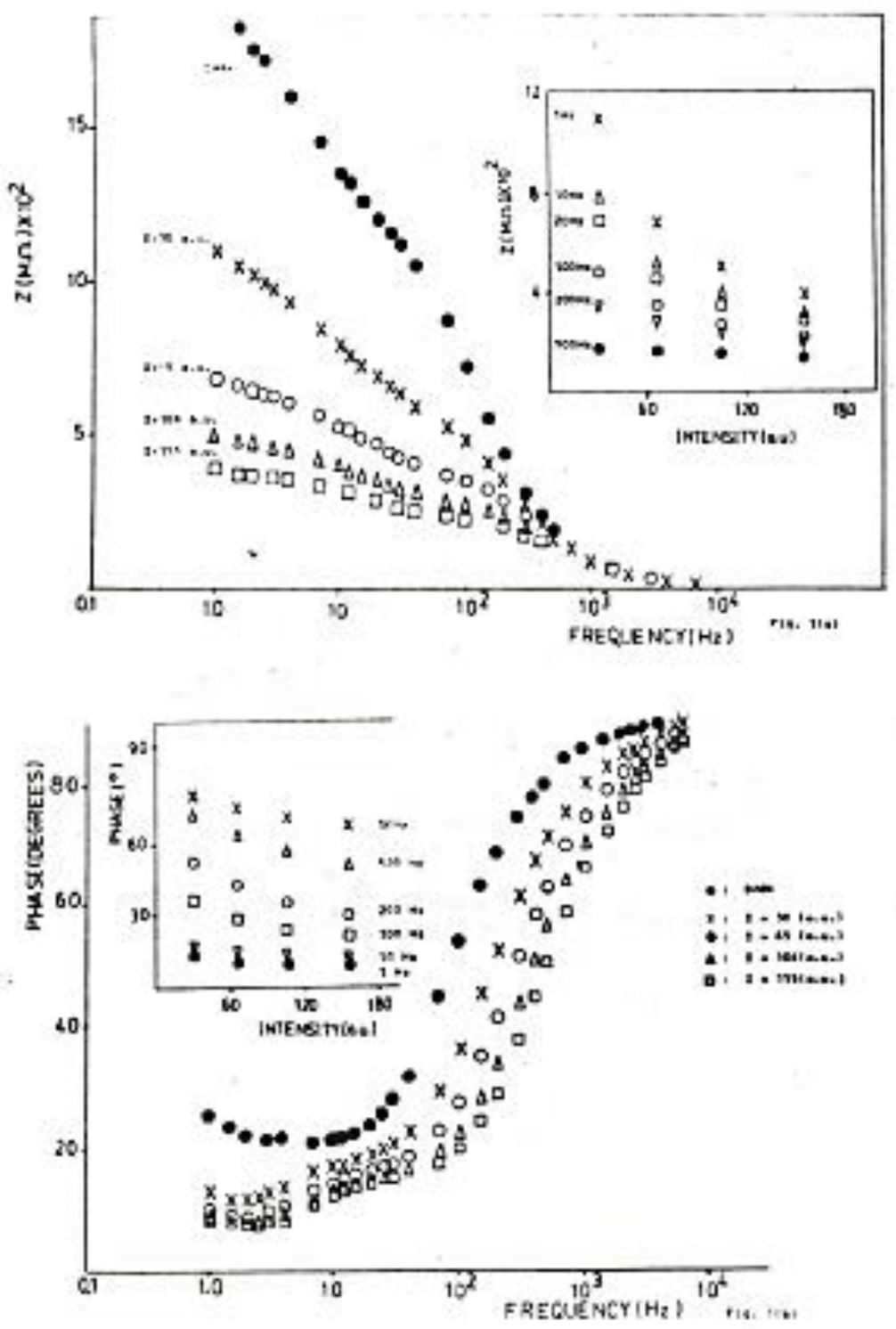

Figure 1: impedance, $z_{1}(18)$ and phase angle, $\Phi,(1 b)$ behaviours as a function af frequency under diffetent light intensities (arbitrary units). The inserts show the variation of $Z$ and $\Phi$ with light intensity, $b$, at various frequencies. 

The rexponse of $\mathrm{Hg}_{2}$ ctystal to the green LEO can be attributed to an excition farmstion $(15,21,26-28)$. The observed decrease in $Z$ with increasing intensity of light may be attributed to the increase in the number of conduction electrans exicited fram the valence band $v$ ia an exciton. Consequently, this increases the electrical and photo-conductivity of the crystal $(14,21,23,26-2 B)$. Since $Z$ is a complex quantity, it may be preferable to study the variation of its real, $Z_{R}$, and imaginary, $Z_{1}$, parts with light intersity. It hes been found that $Z_{R}$ follows a power bw-dependence an light intensity of the form $Z_{R} \propto r^{-m}$, with $m=0,4-0.6$. Simibr dependence of $Z_{1}$ is found with $m$ ranges from $0.7-01,9$. In both cases $i n$ is genefally dependent an frequency. These variations of $Z_{R}$ and $Z_{1}$ with fipht intensity is not casy to interpret, since they ate functions of several crystal parameters. These parameters depend on frequency, light intemsity, peak-to-peak voltoge of the apolicd ac signal, OC bias etc. $(9,10,14-17,23)$. However, detailed arealysis of the netwotks proposed by Bitar et a $L$ (15) and Pegolini and Saura (9) confirms this betaviour of $Z_{R}$ and $Z_{1}$ with $L$. The observed variation of $R_{0}$ and $R_{n}$, the activation resustance of the bw frequency network, with $I_{8 s} C_{9}$ and $C_{d}$, the effective double byer capacitance (15), ate found to be independent of light intensity.

\section{Conchusion}

In this high frequency regian $\langle\mathrm{f}\rangle 3 \mathrm{KHz}\rangle$, the variation of the buk resistance of the crystal with light intensity is masked by the frequency-dependent canduction through the buk capacitance $C_{q}$ which is infeperudent of frequency and light intensity. On the other hand, the rebatively brge variation of both $z_{R}$ and $z_{1}$ with light intensity abserved at bwer frequencies may be understond from a detaikd analysis of the mpuivalent network representing the $\mathrm{Hgl}_{2}$ ccll.

\section{Relerences}

At present at Camputer \& Communications Systems, Amman, Jardan.

1. 15. Nwanczyk, A.J. Dabromeaki, G.S. Huth, 1.G. Bradby, 1.M. Conby, and A.. Aber, SEM Inc. AMF D'Hare (Chicngo), 1., (Pages 9-14) 1\%94

2. L.5. hwank:zyk, A.J. Dabrowaski, G.S. Huth, and TE. Enconamon persaral communication

3. Dabrowski A.J, Hutch G.C. (1978). Toward the energy tesolution limit of mefcutik: iodide in room temperature kow energy $\mathrm{X}$-rBy spectrometery. EEC Trans. on Nucl. Sci. NS-25, No, 1 205-211.

4. Dabruwski A.J. Huth CC. Singh Ma, Exornomou TE, Turkevich Al. (1978). Charncteristic $X$-ray apectra of aodium and magnesium measured at room temperature using mercutic iodide. Appl. Phys. Lett. 33(2), 211-213.

5. Dibrowski AJ, twanczyk 15, Barton 18, Huth GC. Whited R, Drtake, C, Economou IE, Turkevich Al. (1901). Performance of room temperature merouric isdide ( $\mathrm{Hgl}_{2}$ ) detectars in the ultrabw-energy X-tay tegian EEE Ttans. on Nuct. Scl. N5-2a, No. $1,516-540$. 